\title{
Sociobiology and the Comparative Approach: One Way to Study Ourselves
}

\author{
Deborah Ann McLennan
}

Published online: 23 September 2010

(C) Springer Science+Business Media, LLC 2010

\begin{abstract}
This paper is based on my lecture in a macroevolution course I team-teach with Profs. Daniel Brooks and David Evans at the University of Toronto. The lecture has undergone many revisions over the years as I grappled with problems discussing certain areas (e.g., rape as an adaptive strategy, gender "roles"). Eventually, I realized that the problem areas said more about my personal conflicts than they did about the science. This was one of those epiphany moments, a time when I recognized that I was less likely to accept hypotheses that contradicted the way I wanted the world to be and more likely to uncritically accept hypotheses that confirmed my world view. That epiphany, in turn, led me to realize that science is never separate from the personal biases/demons of its practitioners, especially when we are asking questions about the evolution of human behavior. That realization was not novel within the vast literature of sociology and philosophy. But it was novel for me. I was aware of discussions about personal biases clouding scientific interpretation; I just didn't think it applied to me (I absorbed the philosophical discussions without making the connection to "my world"). So, on the heels of that epiphany, the following is a very personal take on the question of teaching sociobiology, based on where my journey, aided by my experience as an ethologist and phylogeneticist and colored by my own history, has taken me.
\end{abstract}

Keywords Sociobiology · Phylogenetics · Comparative phylogenetic approach

\section{A. McLennan $(\triangle)$}

Department of Ecology and Evolutionary Biology,

University of Toronto,

25 Willcocks St.,

Toronto, ON M5S 3B2, Canada

e-mail: deborah.mclennan@utoronto.ca
As human beings, we are infinitely intrigued with ourselves, with trying to explain who we are and where we came from. In phylogenetic terminology, we seem to display a plethora of behavioral autapomorphies ${ }^{1}$ that set us far apart from other animals (Fig. 1). Are we really so different? Why do we often do such seemingly awful things? For most of our history, answering these questions was the sole domain of religion and philosophy. Evolutionary biologists were newcomers to the debate but managed to intensify the discussion by introducing genes into the explanation. With that introduction came the by now famous, often acrimonious, divide between nature and nurture-how much of our behavior is genetically based (that is genetically "determined") and how much a consequence of our environment (and thus capable of being modified)? This question lies at the heart of sociobiological research.

\section{Sociobiology: The First Formulation}

Darwin brought evolution into the quest to understand ourselves and set the foundations for sociobiology when he wrote in The Descent of Man, and Selection in Relation to Sex (my italics):

During many years I collected notes on the origin or descent of man, without any intention of publishing on the subject, but rather with the determination not to publish, as I thought that I should thus only add to the

\footnotetext{
${ }^{1}$ The term autapomorphy simply means a character that is unique to a particular species or taxon (for an extended discussion of phylogenetic terminology, see "How to read a phylogenetic tree" in this issue of Evolution: Education and Outreach).
} 


\section{Our search for identity}

\begin{tabular}{|c|c|c|}
\hline $\begin{array}{l}\text { Some of the negative } \\
\text { things we do }\end{array}$ & $\begin{array}{c}\text { Some of the things we } \\
\text { do that appear to be } \\
\text { evolutionarily counter-intuitive }\end{array}$ & $\begin{array}{c}\text { Some of our more } \\
\text { esoteric traits }\end{array}$ \\
\hline $\begin{array}{c}\text { Class structure } \\
\text { Gender bias } \\
\text { Racism } \\
\text { Rape } \\
\text { Infanticide } \\
\text { Murder }\end{array}$ & $\begin{array}{l}\text { Altruism } \\
\text { Adoption } \\
\text { Depression } \\
\text { Homosexuality }\end{array}$ & $\begin{array}{l}\text { Ethics } \\
\text { Religion } \\
\text { Language } \\
\text { Art }\end{array}$ \\
\hline
\end{tabular}

Fig. 1 Some of the behavioral characters we try to explain in our quest to understand ourselves

prejudices against my views. It seemed to me sufficient to indicate, in the first edition of my 'Origin of Species,' that by this work, "light would be thrown on the origin of man and his history"; and this implies that man must be included with other organic beings in any general conclusion respecting his manner of appearance on this earth...The sole object of this work is to consider, firstly, whether man, like every other species, is descended from some pre-existing form; secondly, the manner of his development; and thirdly, the value of the differences between the so-called races of man (Darwin 1871: 1-3).... I fully subscribe to the judgment of those writers who maintain that of all the differences between man and the lower animals, the moral sense or conscience is by far the most important... This great question has been discussed by many writers of consummate ability; and my sole excuse for touching on it is... because, as far as I know, no one has approached it exclusively from the side of natural history. The investigation possesses, also, some independent interest, as an attempt to see how far the study of the lower animals can throw light on one of the highest psychical faculties of man (Darwin 1871: 70-71).

With these words, Darwin introduced the idea that Homo sapiens was part of the evolutionary tree of life, subject to the same physical and biological influences as all other living creatures. The idea, that we could, indeed must, study ourselves within an evolutionary framework was revolutionary. This is sociobiology. Interestingly though, with these words, Darwin not only demonstrated the power of sociobiology, he also showed what for many became its fatal flaw, assigning "value" to evolutionary differences. Scientifically, Darwin's use of the term value was surprising because he, unlike Lamarck, did not believe that evolution was progressive, nor did he think that evolutionary diversification was driven solely by natural selection. Given that Darwin was, however, an established successful Victorian man living during the height of the British Empire, it is less surprising that he would use the term "value," especially with respect to different "races" of human beings. This duality in his thinking leads us to an important point about doing science in general, one that is especially relevant when we are talking about studying ourselves:

* Scientists do not formulate hypotheses and interpret data in a vacuum. We are all subject to the biases of our upbringing, the culture and times we live in, and the belief systems to which we subscribe. In other words, there is no such thing as absolute objectivity. As scientists, the best we can do is try to acknowledge our own biases and "hidden agendas" and try, to the best of our ability, to eliminate those influences from the way we ask questions and look for answers. We are never completely successful.

Darwin was close to his cousin, Francis Galton, who, among other things, spearheaded the statistical approach to studying the measurement and evolution of intelligence, coined the term nature-nurture, and developed the foundation for eugenics. Galton's eugenics consisted of a utopian society in which the most intelligent men and women would be encouraged to procreate (for a discussion of Galton's life and scientific contributions, see Fancher 2009). At first glance, this might seem mild compared with the later brutalities of Nazi eugenics, but the underlying message was the same because it involved making a judgment about the superiority of individuals (and by extension groups) based on the "value" of traits as judged by the group in power at the time. Darwin revealed the influence of interactions with his cousin and presented, albeit not intentionally, a prime example of why studying the where, how, when, and why of $H$. sapiens behavior within a biological framework is such a controversial approach even today when he wrote:

A most important obstacle in civilized countries to an increase in the number of men of superior class has been strongly insisted on by Mr. Greg and Mr. Galton, namely, the fact that the very poor and reckless, who are often degraded by vice, almost invariably marry early, while the careful and frugal, who are generally otherwise virtuous, marry late in life, so that they may be able to support themselves and their children in comfort. Those who marry early produce within a given period not only a greater number of generations, but... they produce many more children. The children, moreover, that are born by mothers during the prime of life are heavier and larger, and therefore probably more vigorous, than those born at other periods. Thus the reckless, degraded, and often vicious members of society tend to increase at a quicker rate than the provident and generally virtuous members. Or as Mr. Greg puts the case: "The careless, 
squalid, unaspiring Irishman multiplies like rabbits: the frugal, foreseeing, self-respecting, ambitious Scot, stern in his morality, spiritual in his faith, sagacious and disciplined in his intelligence, passes his best years in struggle and in celibacy, marries late, and leaves few behind him ... In the eternal 'struggle for existence,' it would be the inferior and less favored race that had prevailed - and prevailed by virtue not of its good qualities, but of its faults." (Darwin 1871: 173-174)

This discussion was more a proclamation of British attitudes at the time towards Scotland and Ireland than it was robust science. Nowhere are any data presented to support the hypothesized differences between the Scots and Irish; no alternative explanations are entertained other than the implication that such differences are inherent. Every time I read this paragraph to my class, everyone laughsthe controversy seems so far away, such a part of "the past" that no one gets offended. Then I ask the students how they would react if I substituted Israeli/Arab, Pakistani/Indian, "black/white," etc. for "Scots/Irish" and they don't find the paragraph so amusing. In fact, it offends just about everyone; and it offends because personal biases were presented as statements of scientific fact.

\section{Sociobiology: The Second Formulation}

In 1975, E.O. Wilson, a professor of biology at Harvard University, published a book that produced one of the longest and most bitter controversies in the history of science. Sociobiology: The New Synthesis was an amazing feat of scholarship and insight, spanning 27 chapters, only one of which covered $H$. sapiens. That one chapter was enough to spark intense debates, which spilled over from meetings and journals into the press (for excellent discussions, see Segerstråle 1986, 2000, 2001). At the center of the debate was Wilson's summary of studies indicating that behavior had a genetic basis and was thus subject to the influences of natural selection. The idea itself wasn't controversial; researchers had been studying the genetic basis of behavior for decades. But it was one thing to discuss fruit flies, it was quite another to posit that human behavior, from parental care through warfare to ethics and religion, had a genetic component. This wasn't the first time the nature versus nurture controversy had been debated with some heat (the following paragraph is based on Wozniak 2009). When Darwin died, a struggle began between the neo-Darwinists and the neo-Lamarckists. In a nutshell, unlike Darwin, the neo-Darwinists believed that there was only one evolutionary force, natural selection, and that all traits were transmitted through the germ-plasm
(Weismann's theory of heredity: Weismann 1883; 1889). They argued that there could be no such thing as the inheritance of acquired characters (traits that are changed in the parents by the environment and then passed to the offspring) because the gametes were isolated from the environment. Many neo-Lamarckians argued that this perspective smacked of genetic determinism and that it eliminated the actions of culture, will, and consciousness on the evolution of human beings:

If the Weismann idea triumphs, it will be in a sense a triumph of fatalism... [while] civilizing nature will improve the individuals of each generation, its actual effects will not be cumulative as regards the race itself... each new generation must start de novo, receiving no increment of the moral and intellectual advance made during the lifetime of its predecessors. (Osborn 1891: 363)

The accusation of genetic determinism leveled against Wilson's sociobiology was thus not new. What was new was the societal context. A world shocked by the atrocities of Nazi Germany and Stalinist Russia was sensitized to the dark side of research involving genes, behavior, and human beings. Unfortunately, that sensitization led to a parody of Wilson's view, which overlooked two important points. First, Wilson never claimed that human behavior was "all in our genes," only that our behavior had a genetic component and could thus evolve. He advocated the role of consciousness and self-awareness as factors that could override the genetic component underlying, say, warfare. In other words, genes may be, in part, an explanation for some of the awful things we do as human beings, but they are never an excuse, given our ability as rational creatures to understand the consequences of our actions. Second, Wilson made some very important points about how human behavior had been studied in the past and how we could improve on those studies. He began with a critique of the way in which sociobiological research was generally conducted (my italics):

Paradoxically, the greatest snare in sociobiological reasoning is the ease with which it is conducted. Whereas the physical sciences deal with precise results that are usually difficult to explain, sociobiology has imprecise results that can be too easily explained by many different schemes.... In sociobiology, it is still considered respectable to use... the advocacy method... Author X provides a hypothesis to account for a certain phenomenon, selecting and arranging his evidence in the most persuasive manner possible. Author $\mathrm{Y}$ then rebuts $\mathrm{X}$ in part or in whole, raising a second hypothesis and arguing his case with equal conviction. Verbal skills now become a significant 
factor. Perhaps at this stage author $\mathrm{Z}$ appears... siding with one or the other or concluding that both have pieces of the truth that can be put together to form a third hypothesis - and so forth through many journals and over years of time (Wilson 1975: 28).

He then followed this critique with a suggestion for improving the system (my italics):

Few people respond emotionally to debates surrounding ant evolution. Investigating human behavior within a sociobiological framework, however, is a different story.... No theory should be so loved that its authors try to move it out of harm's way. Quite the contrary: a theory that cannot be mortally threatened has little value in science. Most of the art of science consists of formulating falsifiable propositions in just this spirit. The good researcher does not grieve over the death of a particular hypothesis. Since he has attempted to set up multiple working hypotheses, he is committed to the survival of no one of them, but rather is interested to see how simply they can be formulated and how decisively they can be made to compete. (Wilson 1975: 28)

In essence, Wilson advocated that people reading the results of any sociobiological study evaluate the rigor of that study by asking (and answering) six questions:

1. What is the hypothesis?

2. What are the assumptions?

3. What data are being offered?

4. How reliable are the data?

5. Can an alternate hypothesis explain the data?

6. What else is going on (value judgment)? This last question returns us to Darwin's bugaboo of "value." In order to answer this, we have to think about the background of the researcher, what biases he or she might introduce to the study.

Bearing these questions in mind, let's turn our attention to the ways in which we have tried to study ourselves in the years following the publication of Sociobiology.

\section{Studying Ourselves: The Comparative Approach}

The scientific method is a two-step procedure: construct a hypothesis about the way in which something works then set up an experiment to test that hypothesis. In order for the experiment to produce rigorous results, all of the test conditions must be controlled as closely as possible (questions 3 and 4 above). For example, suppose you hypothesize that hummingbirds are attracted to the color red. To test this, you allow hummingbirds access to red, yellow, and blue feeders full of sugar water and record which feeder they visit most often. Before you release the birds, though, you have to make sure that the feeders are the same size and the same distance from the bird, the sugar water is the same concentration in each feeder, the lighting conditions are identical around each feeder, the hummingbirds are all equally hungry, etc. In other words, the only thing that should differ in the experiment is the color of the feeders. Now, try to imagine setting up an experiment to test the hypothesis that human beings are more attracted to red than to any other color. Is the context of the color important (for example, should you use a red food, a red square, a red shirt, red hair)? Should everyone tested be the same age? How do you control socioeconomic factors such as culture, level of education, prior experiences with color, married versus single, with or without children, etc.? Should all women in the study be at the same stage of their estrus cycle? Although we are asking the same question as we were with hummingbirds, the experiment is more difficult to control because there are so many more variables to consider when studying human beings. Now, try to imagine setting up an experiment to study infanticide in human beings. Impossible, right? So how have we traditionally studied something that we cannot manipulate? The most widespread approach involves some type of comparison.

\section{Comparisons Across Wide Taxonomic Scales Based on Homologous Traits}

This approach is based upon the assumption that there are general mechanisms underlying some classes of behavior that are common to all species (as an analogy, think of medical science's use of rodents and primates to study diseases such as cancer and Alzheimer's). For example, psychologists assume that the mechanisms underlying learning are shared (homologous) across all species capable of learned behavior. A homologous trait is a trait that "looks the same" in two or more species because it originated in the common ancestor of those species and was passed from that ancestor to its descendants. For example, mammary glands originated in the ancestor of mammals, which is why all female mammals from platypuses and echidnas to kangaroos and Tasmanian devils to cats and mice and gorillas and sheep suckle their young. So if the learning mechanisms are homologous, studying the ways in which rats and goldfish learn should reveal information that is directly applicable to ourselves. Consider a rat. If he gets a pellet of food (reward) every time he presses a lever, he will eventually decrease his rate of lever pressing-he has learned that the food is there whenever he needs it. But, if he gets rewarded only every so often, he will increase the number of presses - after all, the next time might be IT, the 
food might arrive. The concept of intermittent reinforcement (B. F. Skinner) has been used to explain a variety of human behaviors, the most obvious of which is gambling addiction. After all, the next bet might bring you the jackpot, just as the next lever press might bring the rat his food.

This program is bigger than the careers of just a few researchers because it requires a huge database with which to constantly evaluate the assumption that there are indeed homologous processes underlying the evolution of any particular class of behavior. The assumption of homology is, however, not easily tested, in part because the mechanisms underlying such things as memory, perception, associative learning, and concept learning are still largely unknown. Collaborations between comparative psychologists, developmental biologists, and neurobiologists are beginning to address this issue, but it will take time and ongoing technological advances to collect and analyze the data, coupled with the development of a theoretical framework that will allow us to interpret those data. Until then, the utility of this approach is dependent upon the use of rigorous definitions (e.g., what exactly is memory?) and experiments designed to ask questions that are biologically relevant to the species under investigation. For example, say an animal does not perform well in a trial using a sequence of visual cues to test its memory. Does this mean it is incapable of remembering or that visual cues are not an important part of its umwelt ${ }^{2}$ (perhaps a sequence of olfactory cues would have been more appropriate)? Now, say the animal performs well in the trial. Does this mean that it is "remembering" in the same way that a human being "remembers"? As statisticians so often warn us, correlation (in this case similar outcomes in an experiment using different species) does not mean causation (although it could). As Sarah Shettleworth, one of the researchers involved in developing the area of comparative cognition, wrote:

Attempts to investigate human-like processes in other species often begin with asking yes/no questions and designing pass/fail tests to answer them.... More powerful and convincing are cases in which a more extensive pattern of data can be sought, in effect functional similarity in the mathematical sense of similar relationships between dependent and independent variables, and predictions from different theories of the mechanisms involved pitted against each other in experiments. (Shettleworth 2009:213)

\footnotetext{
$\overline{2}$ The term used by von Uexkull (1934) to call attention to the unique sensory world inhabited by each species, many parts of which are beyond the perceptual capabilities of mere biologists.
}

In other words, studying ourselves based on the assumption of behavioral homology with other species requires precise definitions to avoid miscommunication between researchers, the construction of alternative hypotheses to explain a given phenomenon, rigorous experiments to test those hypotheses, continued advances in delineating the mechanisms underlying the phenomenon, and a healthy dose of skepticism (in fact, all of the things that are required for any research program).

\section{Comparisons Across Wide Taxonomic Scales Based on Convergent Traits}

Convergent characters are defined as similar-looking traits in distantly related organisms that have evolved because of factors other than common ancestry (the traits are not homologous). So, for example, birds and mammals are both warm-blooded (homeothermic), that is, they are able to maintain a constant body temperature even though the temperature in their environment varies. Cold-blooded (poikilothermic) animals like fish, amphibians, snakes, lizards, crocodiles, and turtles cannot maintain an internal temperature; they are physiologically at the mercy of their environment. In a phylogenetic study, you begin with the hypothesis that two traits that "look the same" (e.g., homeothermy) are the same (are homologous). This hypothesis is tested by collecting as many characters as possible and searching for groupings among taxa that are supported by the majority of those characters. So analyzing hundreds of molecular and morphological traits for the large group encompassing ray-finned fishes to amniotes (mammals + reptiles) indicates that birds and mammals are not each other's closest relatives (Fig. 2). Given this, homeothermy must have evolved twice. Our initial hypothesis that homeothermy is homologous in birds and mammals is thus falsified. Once convergent characters have been identified, the quest begins to test the second assumption made about characters of this type: they evolved for the same reason. In other words, the factors influencing the evolution of a particular character (homeothermy) in taxon A (mammals) are the same as the factors influencing the evolution of that character in taxon B (birds).

One of the most famous examples of this approach in sociobiology is the study of infanticide in lions. When a male takes over a pride, he often kills all the cubs. This seemingly horrendous action is hypothesized to persist because it benefits the male in two ways: (1) he doesn't expend energy raising another male's offspring and (2) released from the physiological constraints of nursing, the females quickly come into heat again, which means the male can get on with the business of fathering his own cubs. All of this makes sense evolutionarily given that 


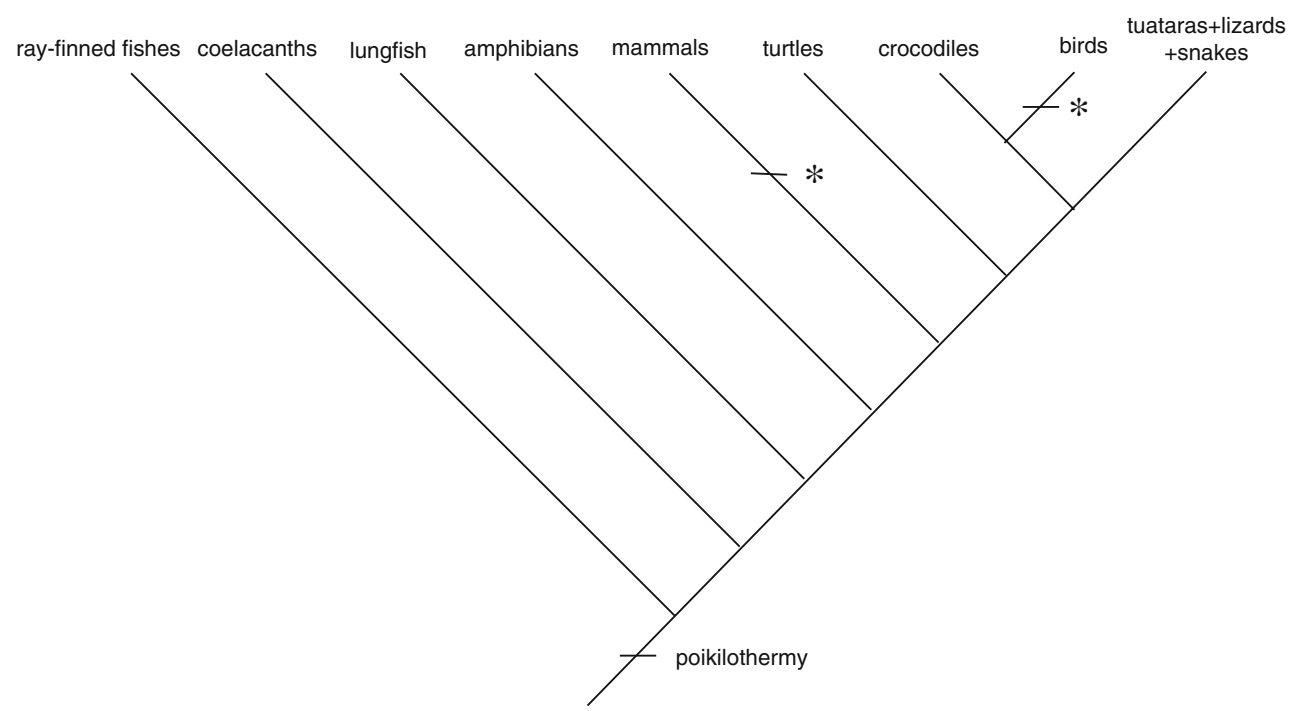

Fig. 2 Identifying convergent evolution on a phylogenetic tree. The hypothesis that the character homeothermy (warm-bloodedness) is the same (=homologous) in mammals and birds is refuted when we place homeothermy on a phylogenetic tree constructed from hundreds of other characters. The phylogenetic patterns indicate that poikilothermy (cold-bloodedness) is the ancestral state for this large group and that homeothermy has originated twice from that state. Homeothermy is thus a convergent trait. Asterisks $=$ homeothermy fitness is based (in part) upon your relative genetic contribution to the future. If we extrapolate from lions to human beings, we would predict that infanticidal individuals should be (a) men who are (b) not related to the children they kill and are (c) in a relationship with the mother. Studies do confirm these predictions; stepfathers kill their stepchildren at much higher rates than do biological fathers (Daly and Wilson 1991, 1994, and references therein). Have we explained the behavior? The answer to this question is a resounding no. We have gained some insight into the evolution of infanticide in $H$. sapiens, some factors that might explain why such a seemingly aberrant behavior persists in our species. But it is obvious that we don't have a complete explanation because, after all, infanticide is not restricted to men, to men unrelated to the children, or even to individuals; sometimes, it is a group phenomenon (e.g., the abortion, killing, or neglect of female children in India and China; Sumner 2009; Coale and Banister 1996).

Wilson cautioned us to beware of assumptions. As mentioned above, the most common assumption that people make when using this type of comparative approach is that if the behavior displayed by species A looks the same as the behavior in distantly related species $\mathrm{B}$, then it must have arisen for the same reasons. This assumption is not easy to validate because it is generally difficult to pinpoint all of the factors surrounding the evolution of any character, let alone one as complicated as infanticide. For example, male lions only hold a pride for three years on average, so they have a very limited window for reproductive opportunities.
The reproductive life span of a human male is much longer, the ability to father offspring outside of any relationship with one woman much greater. This means that some of the basic social factors are not identical in the two species, so it is not surprising that we only uncover one piece of the evolutionary puzzle with regard to infanticide in humans by studying lions.

The major flaw with the "long-distance" comparative approach is that:

* characters do not evolve in a vacuum. As the species being compared become more and more distantly related, the phenotype of the organisms, the contextual basis for the origin of the convergent behaviors, becomes increasingly different. Although humans and lions share much in common because we are both mammals, we are not identical, closer than say humans and fruit flies, but still not the same (Fig. 3). It is therefore not surprising that one species cannot serve as a complete surrogate for another in sociobiological studies of convergent traits, particularly when the phylogenetic distance between the two is great.

\section{Comparisons Across Narrow Taxonomic Scales; Looking at Our Closest Relatives}

One response to the preceding caveat is to focus our sociobiological studies on animals that are as closely related to us as possible - that is, turn our attention to primates in general and the Great Apes in particular. Such an approach will help us pinpoint the origin of some human behaviors. When, for example, did male-based infanticide show up in 
Fig. 3 Diagram showing all the character changes (represented by slash marks) that exist between distantly related animals. This figure is purely heuristic - it is a grossly simplified picture of animal phylogeny and character diversification. Another way to think about the figure is that it is a diagrammatic way of saying that there are vast genetic, physiological, morphological, ecological, and behavioral differences between, say, an insect and a human being

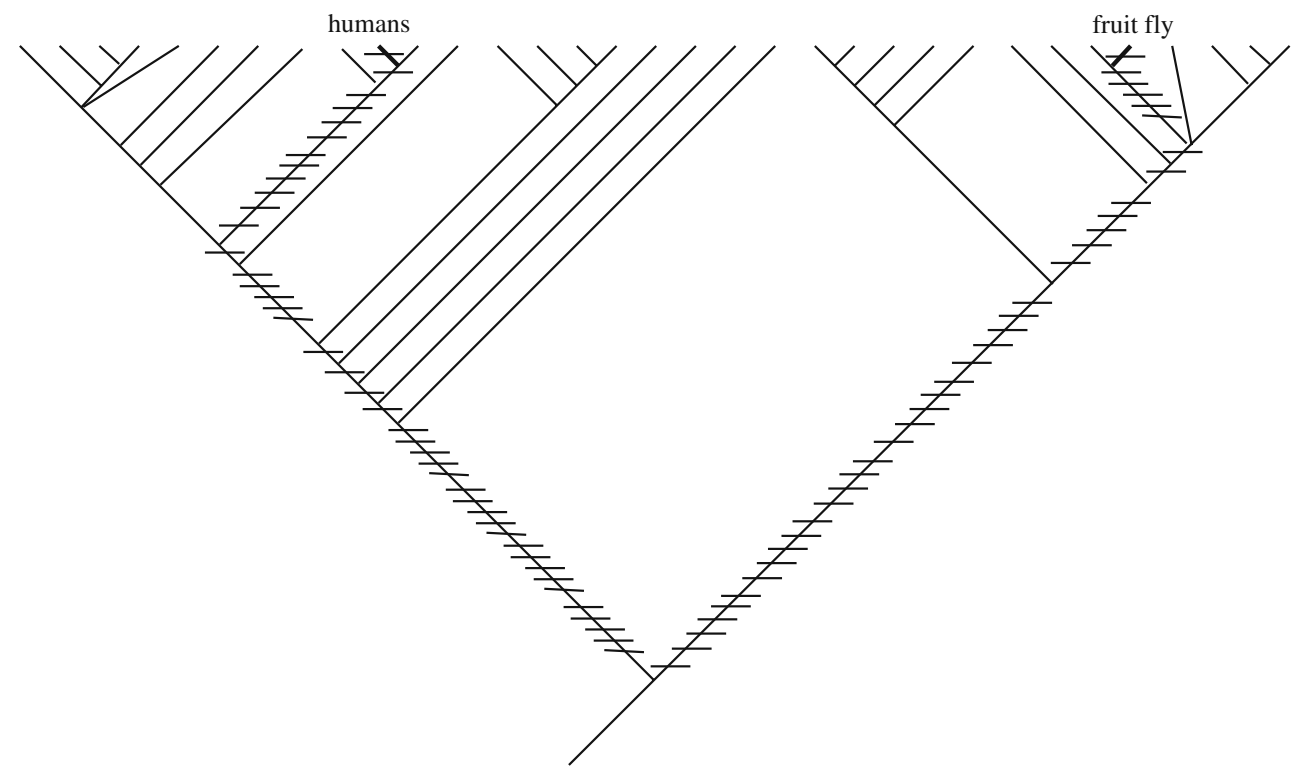

primates? A cursory reading of the literature indicates that the behavior might be an old one, possibly originating in the common ancestor of the Old World monkeys (e.g., baboons, macaques) + Hominoidea (= gibbons + orangutans + gorillas + chimpanzees + us). Do all the species that share this behavior have other characters in common that might provide an underlying explanation for its maintenance over such a long period of time and through so many speciation events? If so, this might explain, in part at least, the maintenance of infanticide in H. sapiens.

I think one of the most powerful results of studying our closest relatives is the realization that we are not as unique as we thought. For example, when many mammals look in a mirror, they respond to their image as if it were just another conspecific. The first time a kitten sees its reflection in a mirror, it raises its paw and bats at "that cat." This has been termed the recognition of "other." Now, if you sedate a mammal (say a gibbon), paint a dot on her forehead, then (when she regains consciousness) allow her to look in a mirror, she acts as usual, curiosity about that other, but nothing else. If, however, you do the same thing with a chimpanzee or an orangutan or a human being, the first thing she does after looking in the mirror is to touch the spot on her forehead, then she turns around to try and see things in the mirror that she has never been able to see! She has made the connection between the reflection and herself. This is called the recognition of "self," something that is clearly older than H. sapiens (reviewed in Suddendorf and Collier-Baker 2009: Fig. 4). Researchers are uncovering the early stages for other "human" traits such as charity, reciprocity, and punishment for cheating (de Waal 1996), tool use and cultural transmission, warfare, language, and face-to-face copulation in our primate roots. All in all, losing our uniqueness is not so unexpected. After all, we are but a branch on the evolutionary tree of life, not a separate shrub!

The Great Apes have so much to show us about ourselves. They are indeed so close to us in many ways that many people are beginning to question just how ethical it is to use them as test subjects. New Zealand, the Netherlands, the UK, Sweden, Germany, and Austria currently ban using Great Apes in research. The Great Ape Project, an international organization of primatologists, psychologists, ethicists, and biologists, is campaigning for the United Nations to grant three basic rights to all Great Apes: the right to life, protection of individual liberty, and the prohibition of torture (see Wikipedia entry: http://en. wikipedia.org/wiki/Great_Ape_Project). If you have any doubts about the importance of such a declaration, get Frans de Waal's book Bonobo, The Forgotten Ape (1998) and look at the picture of a bonobo female in a classic yoga pose, sitting with one leg and arm stretched upwards and sideways, clasping her pointed toes with her fingers. Looking at the photograph is like looking at yourself, at least that's the way I find it. Primatologists like Jane Goodall, Birute Galdikas, Dian Fossey, and Franz de Waal have shown us that we can learn a substantial amount about Great Ape behavior in the field. Of pressing concern now is the fact that all Great Ape populations are endangered or critically endangered in the wild and all have decreasing populations, except, of course, for H. sapiens (IUCN 2008 Red List: www.iucnredlist.org). If the Great Apes go extinct, we will lose more than just a unique component of this planet's biodiversity; we will lose the ability to learn much about ourselves. We will become evolutionary orphans. 
Fig. 4 Phylogeny for the Hominoidea (gibbons + Great Apes) showing the hypothesized point of origin for self-awareness, indicating that awareness of yourself as an individual is older than human beings. This is just one of many traits that we share with our closest relatives. We are not as unique as we might think

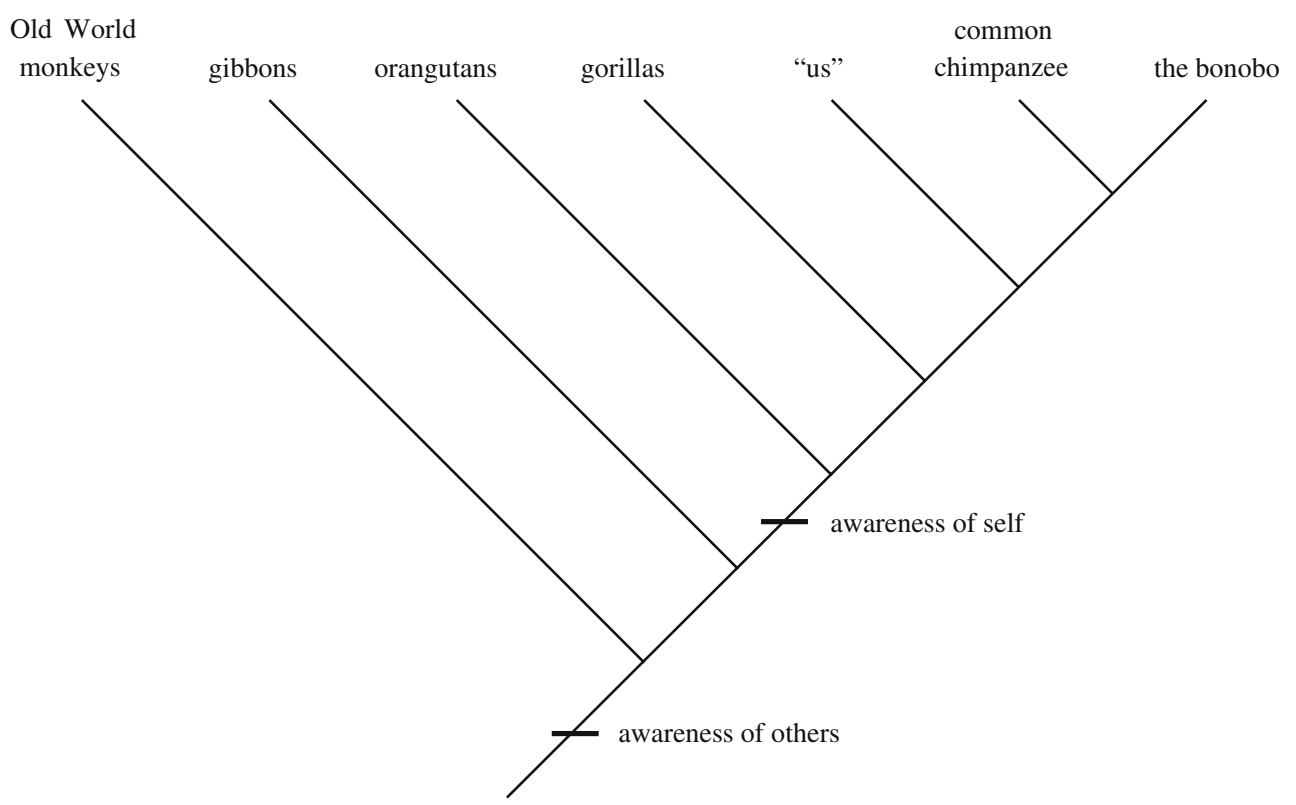

Comparisons Across Narrow Taxonomic Scales; Looking Within Ourselves

We do, of course, have some characteristics that are unique to Homo, traits that originated somewhere during the history of our genus and that cannot be studied by reference to other groups, no matter how closely related. This we can do only by reference to ourselves, which requires that we narrow the focus of our research beam even more. Unfortunately, with the exception of $H$. sapiens, all of the members of the subfamily Hominina, which includes genera such as Homo and Australopithecus, are extinct, so we can never pinpoint the origins of these unique traits. We can, however, study the maintenance of these traits by examining the conditions under which they are expressed in different groups of human beings.

This pursuit has traditionally been the domain of cultural anthropology and thus has not always been viewed within an evolutionary framework. To do this, we would need to construct a robust phylogeny for $H$. sapiens. Technically, this is not problematical: phylogeographers have been using genetic data from the mitochondrion and nucleus to study population interrelationships within widespread species for over 10 years (Avise 2000). The problem lies in the interpretation of those data, with our disposition to classify life forms as either "primitive" or "advanced." The idea of a linear scala naturae or "Chain of Being" was first proposed by Aristotle, who theorized that the chain moved from nonliving matter to plants to insects to animals with "non-perfect" eggs (e.g., fish) to animals with perfect eggs (e.g., birds) to mammals to man to god (http://scienceworld.wolfram.com/ biography/Aristotle.html). The details of the chain changed across the millennia (for a painting of the chain from 1579, see http://en.wikipedia.org/wiki/Great_chain_of_being), but one thing was invariant: we always put ourselves just one step from the top, below god but above all other forms of life.

Darwin did not believe that evolution produced a progressive, linear Chain of Being. He even made a note to himself never to use the terms "higher" or "lower" when speaking about different forms of life (Tattersall 2009). The very process of natural selection, however, required that one trait replace another, leading to the assessment that the second trait was somehow "better" than the first. Take this reasoning one step further and you have the situation in which people argue that some species or groups are "better than," "more fit than," and "superior to" other species (the modern scala naturae). This type of attitude is reflected, as are all attitudes, in language; so we speak of "primitive" (e.g., sharks) and "advanced" (e.g., human beings) species. If you think about it though, sharks have been on this planet about 430 million years longer than $H$. sapiens. They have specialized cells called the ampullae of Lorenzini that are extremely sensitive to electric fields. Smooth dogfish can detect current as tiny as five billionths of a volt per centimeter-the ionic leakage across the gills of a buried flounder. Hardly "primitive" but definitely a different umwelt than that occupied by $H$. sapiens.

The point here is that, as Darwin realized, there is no objective way to define or measure the terms "primitive" or "advanced." Organisms are a mosaic of thousands of traits, so the argument about one trait being "better" than another is impossible to apply above the level of the individual character; and even at the level of the character, it is only a relative judgment because the performance of a trait varies through space, with changing environmental conditions and challenges, and through time; evolution is not static and absolute, it is relative. So to establish a "fitness" scale for species, you would have to measure the efficacy of each 
trait in species A and species B, then add up all the pluses and minuses to produce an overall ranking. More importantly, even if you could surmount the staggering logistical problems and produce such a ranking, you would constantly have to reevaluate and readjust that number as conditions around the species changed. The take-home message is simple: species are not "primitive" or "advanced," "inferior" or "superior"; they are simply different, in part because each has adapted to a slightly different environment.

Now, extrapolate from (faulty) judgments about better or worse in terms of species to "superior" or "inferior" in terms of populations or lineages and you can see what the problem would be with interpreting a phylogeny for $H$. sapiens. There would be a tendency to assign the term "primitive" to groups near the base of the tree, to believe that the groups at the "tip" of the tree are somehow superior, when what we are really talking about is a complicated mosaic of groups that share many traits (in fact most) in common but have diverged as each group meets its own unique environmental challenges. A phylogeny of $H$. sapiens would be an incredibly powerful tool that we could use to explore the vast database amassed by cultural anthropologists, to begin answering questions about the evolution of traits unique to human beings. Anyone who undertakes such a project, however, must emphasize repeatedly that there is no such thing as evolutionary superiority, only evolutionary differences.

\section{Summary}

It is not easy to study ourselves for the obvious reason that it is difficult to study all the factors influencing the way in which a system works from inside the system. Part of the reason for the difficulty is that scientists are never impervious to the society in which they are born. We all bring our own individual biases and blinkers into a study and that affects the ways in which we ask questions, search for answers and interpret the data we collect. The impact of this problem is amplified when we study ourselves, particularly our own behavior. Does this mean the quest to understand ourselves is futile? No, I don't think so. Sociobiology, which I widely define to include all comparative evolutionary approaches to studying behavior (so this includes evolutionary studies in biology, psychology, psychiatry, anthropology, and sociology), provides us with tools to uncover some of the data needed to address the problem. Molecular biology adds more data with the demonstration that the "one gene-one trait" metaphor grossly oversimplifies what is actually happening during development. For example, substances laid down in the cytoplasm of the egg can have a profound impact on early developmental processes independent of the genotype of the developing embryo. This makes total genetic control of complex human behaviors, of any complex behavior for that matter, extremely unlikely. In other words, a genetic component to behavior does not necessarily mean that expression of the behavior is genetically determined. It is tempting to say that our behavioral fates are influenced by, but not written in, our genes, but I think that a more realistic statement is that we currently know next to nothing about the mechanisms underlying human behavior. What we do know is that "nature versus nurture" always was an artificial dichotomy and, because it is such a simplistic vision, can be dangerously misleading when discussing something as emotionally charged as why we do what we do. The development and expression of any complex behavior will most likely always be an intricate interaction between genes and the environment, all the components of which will not be easy to discover (for a comprehensive discussion of the nature-nurture problem, see Bateson 2001).

One of the wonderful and disturbing things about science is that we never uncover the truth. At the very best, we find an explanation that best fits the data we have at a particular point in space and time. There is no guarantee that what we discover about ourselves during this evolutionary journey will always be comfortable or "acceptable." All we can do, what we must do, is strive to judge all studies of human behavior according to the six questions delineated previously, to be as rigorous as possible, and to try never to let personal judgments of "value" color the way we interpret data.

Acknowledgments To all of the students in the Macroevolution course, both at the University of Toronto and at Stockholm University, whose questions and enthusiasm encouraged me to keep exploring the "problem of sociobiology," I say thank you so much. Thanks also go to Daniel Brooks for organizing this issue, Niles Eldredge for his continuing positive attitude towards EEO contributors, and two anonymous reviewers whose insights greatly improved the original manuscript.

\section{References}

Avise JA. Phylogeography. Cambridge: Harvard University Press; 2000.

Bateson P. Where does our behaviour come from? J Biosci. 2001;26:561-70.

Coale AJ, Banister J. Five decades of missing females in China. Proc Am Philos Soc. 1996;140:421-50.

Daly M, Wilson MI. A reply to Gelles: stepchildren are disproportionately abused, and diverse forms of violence can share causal factors. Hum Nat. 1991;2:419-26.

Daly M, Wilson MI. Some differential attributes of lethal assaults on small children by stepfathers versus genetic fathers. Ethol Sociobiol. 1994;15:207-17.

Darwin C. The descent of man and selection in relation to sex, vol. I. London: John Murray; 1871. 
de Waal F. Good natured: the origins of right and wrong in humans and other animals. London: Harvard University Press; 1996.

de Waal F. Bonobo, the forgotten ape. Los Angeles: University of California Press; 1998.

Fancher RE. Scientific cousins: the relationship between Charles Darwin and Francis Galton. Am Psychol. 2009;64:84-92.

Osborn HF. The present problem of heredity. Atlan Mon. 1891;67:353-64.

Segerstråle U. Colleagues in conflict: an in-vivo analysis of the sociobiology controversy. Biol Philos. 1986;1:53-88.

Segerstråle U. Defenders of the truth: the sociobiology debate. Oxford: Oxford University Press; 2000.

Segerstråle U. World views and Trojan horses in the sociobiological debate 1. The sociobiology debate. J Biosci. 2001;26:54954.

Shettleworth SJ. The evolution of comparative cognition: is the snark still a boojum? Behav Processes. 2009;80:210-7.
Suddendorf T, Collier-Baker E. The evolution of primate visual selfrecognition: evidence of absence in lesser apes. Proc Royal Soc B Biol Sci. 2009;276:1671-7.

Sumner MM. The unknown genocide: how one country's culture is destroying the girl child. Int J Nur Pract. 2009;15:65-8.

Tattersall I. Charles Darwin and human evolution. Evo Edu Outreach. 2009;2:28-34.

Von Uexkull J. Strafzuege durch die Umwelten von Tieren und Menschen. Berlin: Springer; 1934.

Weismann A. Über die vererbung. Jena: Fischer; 1883.

Weismann A. Essays upon heredity and kindred biological problems (2 vols.). Oxford: Clarendon; 1889.

Wilson EO. Sociobiology: the new synthesis. Cambridge: Harvard University Press; 1975.

Wozniak RH. Consciousness, social heredity, and development: the evolutionary thought of James Mark Baldwin. Am Psychol. 2009;64:93-101. 